SSCMT

Journal of Sustainable Construction

Materials and Technologies
Journal of Sustainable Construction Materials and Technologies

J. Sustain. Construct. Mater. Technol. 3(2) (2018) 221-229

http://www.eds.yildiz.edu.tr/jscmt

\title{
Abrasion Resistance and Strength Properties of Non-Fibrous and Steel Fiber Reinforced Mortars With Different Aggregates
}

\author{
Mustafa Karagöz ${ }^{1, *}$, Orhan Canpolat ${ }^{1}$, Mukhallad M. Al-mashhadani ${ }^{1}$, \\ Yurdakul Aygörmez ${ }^{1}$, Mucteba Uysal ${ }^{2}$

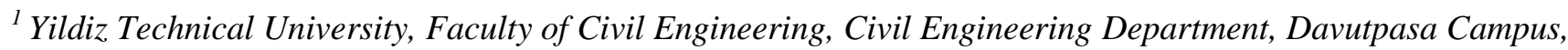 \\ Istanbul, Turkey \\ ${ }^{2}$ Istanbul University, Engineering Faculty, Civil Engineering Department, Avcilar campus, Istanbul, Turkey
}

Received January 8, 2018; accepted April 10, 2018

\begin{abstract}
In this paper, an experimental investigation was carried out to study the effect of using different aggregates on the abrasion resistance, flexural and compressive strengths of the manufactured OPC mortars. Waste foundry sand and calcareous limestone were used as a partial replacement with the standard sand. The aforementioned procedure was conducted with and without the reinforcement of steel fibers in order to inspect the significance of fibers on the intended tests. Results revealed the fact that using fiber reinforcement and waste foundry sand together proved to be in benefit of improving the characteristics of the resulted matrix. MIX 3 yielded the best results in terms of strength properties and abrasion resistance. Moreover, the mixes with limestone aggregates presented a better performance when compared to the control specimen.
\end{abstract}

Keywords: Mortar, Strength Properties, Fibers, Foundry Sand, Abrasion Resistance

\section{Introduction}

Cementitious binders, being the most extensively used construction materials in the world, are the backbone of all the construction and development activities around the world. Each of the primary constituent of concrete or mortar has an environmental impact, to a different extent. Being used in enormous quantity around the world, it gives rise to different sustainability issues [1].

There is a rising concern about over-exploitation of natural sand and gravels, constituents of concrete. The massive use of concrete due to boom in urbanization and industrialization has resulted in the overextraction of river sand from the river bed. This has called for several harmful consequences, including increased river bed depth, lowering of the water table, exposure of bridge substructures, major impact on rivers, deltas and coastal and marine ecosystems, loss of land through river or coastal erosion and decrease

\footnotetext{
${ }^{1}$ Corresponding Author:

E-Mail addresses: mustafa.karagoz@hotmail.com (M. Karagöz)

https://doi.org/10.29187/jscmt.2018.23
} 
in the amount of sediment supply. Furthermore, the subsistence of construction industry has been severely affected due to the restrictions in the extraction of sand from the river resulting in rise of the price of sand. Thus, it has become imperative to look for alternative to natural river sand [2].

Increasing population and advancements in technology have led to increase in waste production. Thus, many researchers and scientists all over the world are finding new ways to reduce these wastes or as a better alternative to use them as resources with added values. Since past several decades, various industrial wastes are being studied extensively as a substitute/replacement material for fine aggregate. Substitution of alternative materials in concrete has been found to improve both the mechanical and durability properties, and this practice can lead to the sustainable concrete development [1].

Waste foundry sand (WFS) is one such promising material which needs to be studied extensively as substitute of fine aggregates in concrete. It is a by-product from the ferrous and non-ferrous metal casting industries with ferrous foundries producing the most sand. It is characteristically sub-angular to round in shape and has high thermal conductivity which makes it suitable for molding, casting operations. Several researchers have studied foundry sand in recent years, some of whose work has been listed in the following:

Guney et al. (2006) investigated the re-use of foundry sand modified mixtures for sub-based layers of highways.. Korac et al. (2006) investigated the used-foundry sand in making of plaster mixture. El Haggar and El Hatow (2009) investigated the use of rejected and un-recyclable plastics with used-foundry sand for manhole covers and its base. Gao and Drummond (1999), Ferraris et al. (2001), and Colombo et al. (2003) have reported the use of waste foundry sand for the inertization and re-use of waste materials by vitrification. In addition, Raupp-Pereiraa et al. (2004) investigated the refractory mortars made of waste foundry sand.

On the other hand, the use of limestone in the construction industry has been increasing due to benefits as aggregate. Some of these benefits include good strength, low possibility of alkali-silica reaction and the decrease in drying shrinkage in concrete. Aquino et al. [3] discussed the consumption and general characteristics of the limestone aggregate in USA and Japan. The experiments were conducted on mixtures of different proportions of fine limestone and sand at different water/cement (W/C) ratios. The water absorption and porosity of fine limestone and sand were measured to find a relation with the water entrapped in the pores of the surface of the rock and the drying shrinkage. The results showed the increases in the compressive and flexural strengths and modulus of elasticity when the fine limestone proportion increases in the mixture. The most outstanding results are found on the drying shrinkage, which decreases considerably with the increase in fine limestone proportions.

Brittleness and low tensile strength are major drawbacks of concrete. The product obtained by randomly adding a small quantity of short fibers into a cementitious matrix is known as fiber reinforced composite (FRC) and improve many of its properties, such as compressive, split tensile, flexural, shear, impact, fatigue and abrasion strength, deformation capacity, load bearing capacity after cracking, and toughness properties [4].

In the studies conducted by Bentur [5,6], crack propagation that occur due to internal stress in concrete were prevented by the use of steel fibers in conventional concrete. This was attributed to stress transfer capability of fibers. This behavior of fibers dominates the use of steel fiber reinforced concrete (SFRC) compared to the plain concrete.

Pierre et al [7] carried out an experimental study in which test results indicate that the addition of a relatively low dosage of steel microfibers $(2.5 \%$ by volume) significantly increases the mechanical properties of cement pastes.

This experimental investigation aimed to study the effect of waste foundry sand and limestone aggregates on non-fibrous and steel reinforced mortars in terms of abrasion resistance and strength properties.

\section{Materials Characterization}


The type of cement used in all mortar series was CEM I 42.5R, its properties are presented in Table 1. Standard sand which is correspondent to BS EN 196-1[8] and Rilem Cembureau standard was used in this study. The chemical composition of the used waste foundry sand is given in Table 2 while Details of straight steel fibers are presented in Table 3.

Table 1. Chemical, physical and mechanical properties of cement

\begin{tabular}{|c|c|c|c|c|}
\hline Chemical & $\%$ & \multicolumn{3}{|c|}{ Physical Properties } \\
\hline $\mathrm{SiO}_{2}$ & 20.14 & $\begin{array}{l}\text { Specific gravity } \\
\left(\mathrm{g} / \mathrm{cm}^{3}\right)\end{array}$ & \multicolumn{2}{|c|}{3.15} \\
\hline $\mathrm{Al}_{2} \mathrm{O}_{3}$ & 5.04 & $\begin{array}{l}\text { Vicat time of setting } \\
(\text { min) }\end{array}$ & 165 (Initial) & 199 (Final) \\
\hline $\mathrm{Fe}_{2} \mathrm{O}_{3}$ & 3.78 & $\begin{array}{c}\text { Compressive } \\
\text { strength (MPa) }\end{array}$ & 40 (7 days) & 51 (28 days) \\
\hline $\mathrm{CaO}$ & 63.92 & & & \\
\hline MgO & 1.35 & & & \\
\hline $\mathrm{SO}_{3}$ & 2.84 & & & \\
\hline Trace Elements & 0.58 & & & \\
\hline $\begin{array}{c}\text { Loss on } \\
\text { ignition(LOI) }\end{array}$ & 1.35 & & & \\
\hline Free $\mathbf{C a O}$ & 1.35 & & & \\
\hline Chloride & 0.0096 & & & \\
\hline
\end{tabular}

Table 2. Chemical composition of the waste foundry sand

\begin{tabular}{|l|l|}
\hline Constituent & Value (\%) \\
\hline $\mathrm{SiO}_{2}$ & 98 \\
\hline $\mathrm{Al}_{2} \mathrm{O}_{3}$ & 0.9 \\
\hline $\mathrm{Fe}_{2} \mathrm{O}_{3}$ & 0.2 \\
\hline $\mathrm{CaO}$ & 0.18 \\
\hline $\mathrm{MgO}$ & 0.01 \\
\hline $\mathrm{SO}_{3}$ & 0.01 \\
\hline $\mathrm{Na}_{2} \mathrm{O}$ & 0.04 \\
\hline $\mathrm{K}_{2} \mathrm{O}$ & - \\
\hline $\mathrm{TiO}_{2}$ & - \\
\hline $\mathrm{Mn}_{2} \mathrm{O}_{3}$ & - \\
\hline $\mathrm{SrO}$ & - \\
\hline $\mathbf{L O}$ & - \\
\hline
\end{tabular}

Table 3. Properties of straight steel fibers.

\begin{tabular}{|c|c|c|c|c|c|}
\hline $\begin{array}{c}\text { Fiber } \\
\text { Type }\end{array}$ & $\begin{array}{c}\text { Length } \\
(\mathbf{m m})\end{array}$ & $\begin{array}{c}\text { Diameter } \\
(\mathbf{m m})\end{array}$ & $\begin{array}{c}\text { Specific } \\
\text { Gravity }\end{array}$ & $\begin{array}{c}\text { Nominal Tensile } \\
\text { Strength (MPa) }\end{array}$ & Aspect ratio \\
\hline \hline STEEL & 6 & 0.17 & 7.85 & 2100 & 35.29 \\
\hline
\end{tabular}




\section{Experimental procedure}

Cement and sand were mixed prior to the water addition. Fibers (in case of fiber reinforced mixes) were then added to the resulted mortar. Foundry sand was replaced with Rilem sand by a percentage of $10 \%$ in mix 2 and mix 5 whereas mix 3 and mix 6 contained only limestone. Fibers were added as a volume fraction ratio of $1.5 \%$. A total of six mixes were manufactured in this work, mixes details and proportions are given in table 4

Table 4. Mixing proportions of the manufactured mortars

\begin{tabular}{|l|l|l|l|l|l|l|l|}
\hline $\begin{array}{l}\text { No. of } \\
\text { Mixes }\end{array}$ & $\begin{array}{l}\text { Sand } \\
(\mathbf{g m})\end{array}$ & $\begin{array}{l}\text { Foundry } \\
\text { sand }(\mathbf{g m})\end{array}$ & $\begin{array}{l}\text { Limestone } \\
(\mathbf{g m})\end{array}$ & $\begin{array}{l}\text { Steel } \\
\text { fibers(gm) }\end{array}$ & $\begin{array}{l}\text { Cement } \\
(\mathbf{g m})\end{array}$ & Water(ml) & $\begin{array}{l}\text { w/c } \\
\text { ratio }\end{array}$ \\
\hline $1($ control) & 1350 & - & - & - & 450 & 202.5 & 0.45 \\
\hline 2 & 1215 & 135 & & - & 450 & 202.5 & 0.45 \\
\hline 3 & - & - & 1350 & - & 450 & 202.5 & 0.45 \\
\hline 4 & 1350 & - & - & 90 & 450 & 202.5 & 0.45 \\
\hline 5 & 1215 & 135 & - & 90 & 450 & 202.5 & 0.45 \\
\hline 6 & - & - & 1350 & 90 & 450 & 202.5 & 0.45 \\
\hline
\end{tabular}

After mixing process, $50 \mathrm{~mm}$ side cubes, $40 \times 40 \times 160$ prisms, and $71 \mathrm{~mm}$ side cubes were cast for performing compressive strength, flexural strength, and abrasion resistance tests. After casting process the specimens were left to dry for 24 hours in laboratory conditions [a temperature of $\left(23 \pm 2{ }^{\circ} \mathrm{C}\right)$ and a relative humidity of $(50 \pm 4) \%$. Compressive strength test was carried out after 7 and 28 days using the $50 \mathrm{~mm}$ side cubes, the test procedure was done according to ASTM C 109 [9]. Flexural strength test was also conducted after 7 and 28 days using the prismatic samples according to the flexural test procedure mentioned in ASTM C 348 [10].

Böhme test (EN 1338) [11] was used for assessing the abrasion resistance of concretes. Test was performed on three specimens for each mixture. The specimens were initially dried to constant mass at a temperature of $105 \pm 5^{\mathrm{O}} \mathrm{C}$. Specimens were then placed on the test track of a $750 \mathrm{~mm}$ diameter rotating disc on which a $20 \mathrm{~g}$ of standard abrasive (artificial corundum) is poured. The specimens were then subjected to grinding for 22 revolutions under a constant load of $294 \pm 3 \mathrm{~N}$ and $30 \mathrm{rev} / \mathrm{min}$ rotation speed. The specimens were tested for 16 cycles, each consisting of 22 revolutions.

\section{Results and discussion}

\subsection{Strength properties}

Results of compressive and flexural strength are shown in Table 5 and Figures 1 and 2. In general, the addition of fibers proved to be beneficial in improving the strength properties of the manufactured mortars. The mix which contained foundry sand and steel fibers showed the best performance in terms of flexural and compressive strengths. When compared to control sample, mix 5 yielded an improvement of $22.33 \%$ and $35.56 \%$ in terms of compressive strength and flexural strength, respectively. On the other hand, the mix which contained limestone showed generally an accepted behavior in compressive strength and a significant improvement in flexural strength. This conclusion gives an indication that the existence of fibers along with waste materials could be beneficial from the environmental and the economical perspectives in addition to the strength aspect. 
Table 5. Flexural and Compressive Strength Results Of The Manufactured Mortars

\begin{tabular}{|c|c|c|c|c|c|c|c|c|}
\hline \multirow{2}{*}{$\begin{array}{l}\text { No. of } \\
\text { Mixes }\end{array}$} & \multicolumn{2}{|c|}{$\begin{array}{c}\text { flexural strength } \\
\text { (MPa) }\end{array}$} & \multicolumn{2}{c|}{$\begin{array}{c}\text { compressive } \\
\text { strength (MPa) }\end{array}$} & \multicolumn{2}{|l|}{} & \\
\cline { 2 - 9 } & 7 Days & 28 Days & 7 Days & 28 Days & \multicolumn{2}{c|}{ Flex. Imp. (\%) } & \multicolumn{2}{|c|}{ Comp. imp. (\%) } \\
\hline mix 1 & 5.803 & 6.13 & 24.61 & 36.04 & 7 Days & 28 Days & 7 Days & 28 Days \\
\hline mix 2 & 5.144 & 6.449 & 24.76 & 34.75 & -11.36 & 5.20 & 0.61 & -3.58 \\
\hline mix 3 & 6.486 & 8.292 & 27.53 & 33.34 & 11.77 & 35.27 & 11.87 & -7.49 \\
\hline mix 4 & 7.331 & 7.521 & 31.39 & 38.09 & 26.33 & 22.69 & 27.55 & 5.69 \\
\hline mix 5 & 6.662 & 8.31 & 35.876 & 44.09 & 14.80 & 35.56 & 45.78 & 22.34 \\
\hline mix 6 & 7.95 & 8.349 & 29.229 & 35.36 & 37.00 & 36.20 & 18.77 & -1.89 \\
\hline
\end{tabular}

Notes:

*Comp. imp.: Compressive improvement.

**Flex. imp. : Flexural improvement.

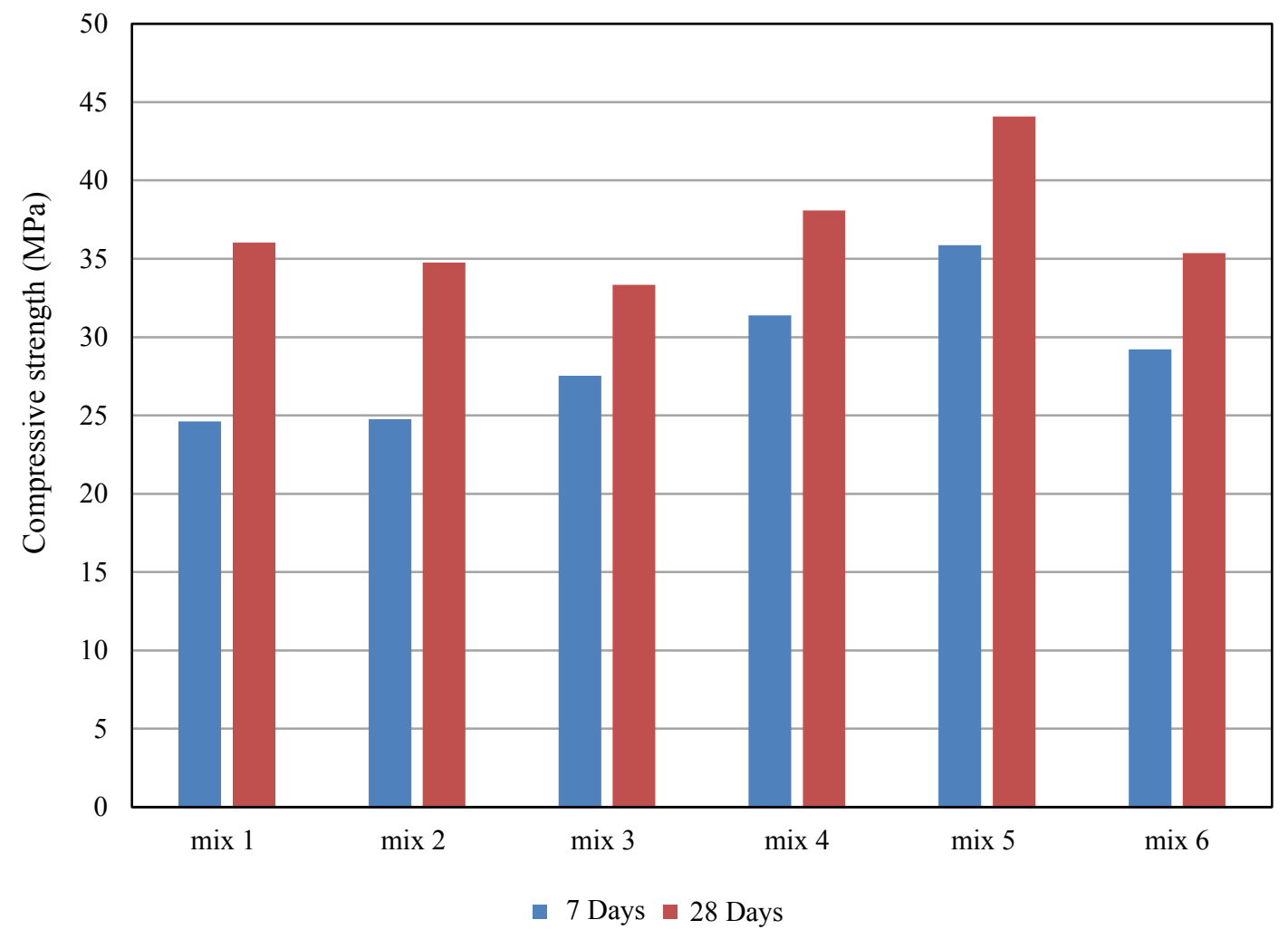

Fig. 1. Compressive strength (MPa) 


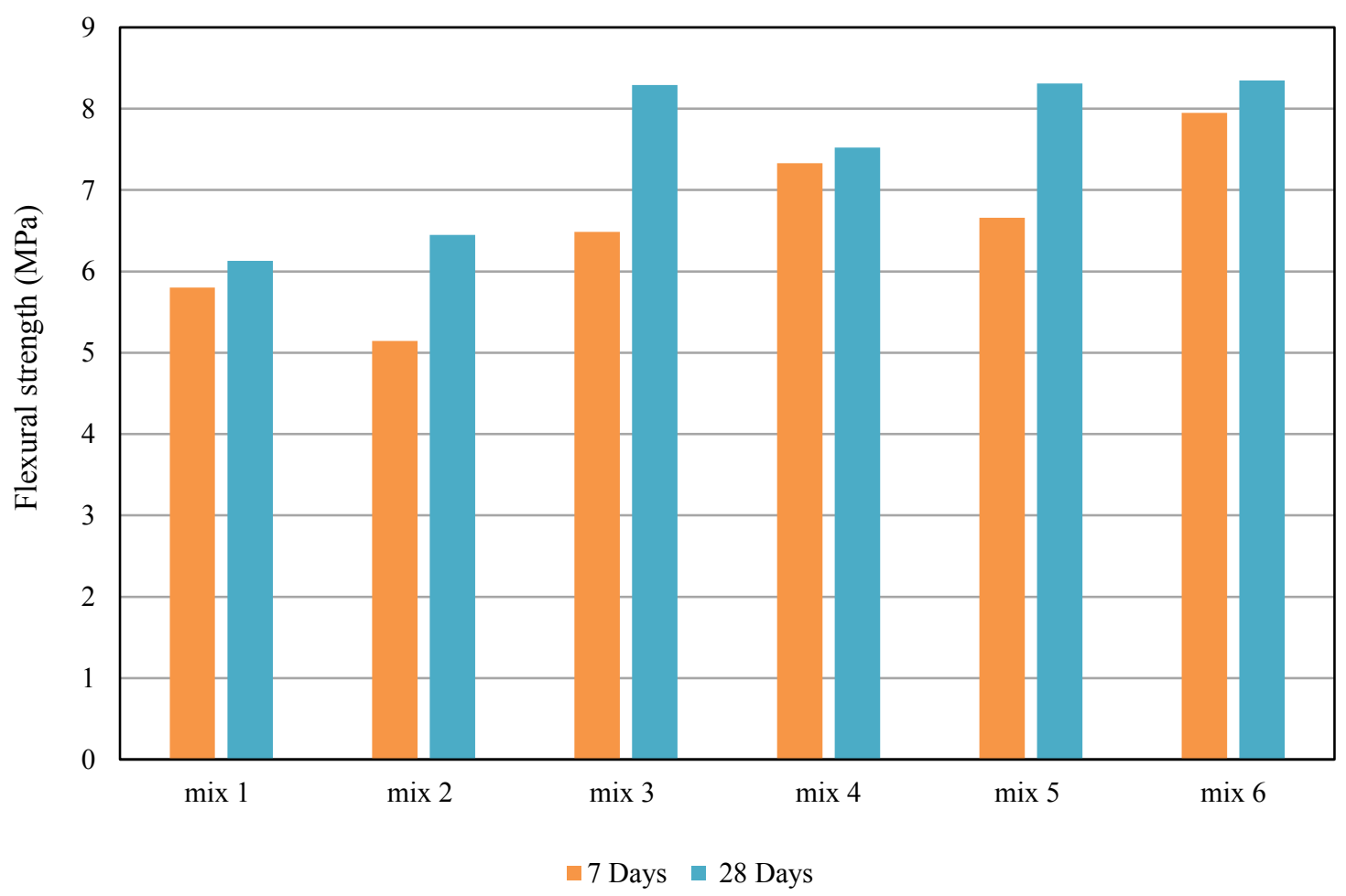

Fig. 2. Flexural strength (MPa)

\subsection{Abrasion resistance}

Results of weight loss and length change due to abrasion are shown in figures 3 and 4 . The mixes generally presented convergent results in terms of length change except mix 5 which yielded the least length change $(0.92 \mathrm{~mm})$ and an improvement percentage of $1.29 \%$ in comparison to the control sample. Also, the other mixes yielded better results when compared to the control sample. In terms of weight loss, a performance similar to that of length change was obtained from mix 5 by showing the least weight loss $(3.47 \mathrm{gr})$ and the least percentage of weight loss $(0.48 \%)$. It is noteworthy that the mixes which contained foundry sand and limestone generally yielded better results when compared to the control sample in both non-fibrous and fiber reinforced mixes. This leads to a conclusion that using such waste materials is of benefit in improving the abrasive behavior of the cementitious composites. Percentages of weight loss and length change are given in figures 5 and 6 , respectively. 


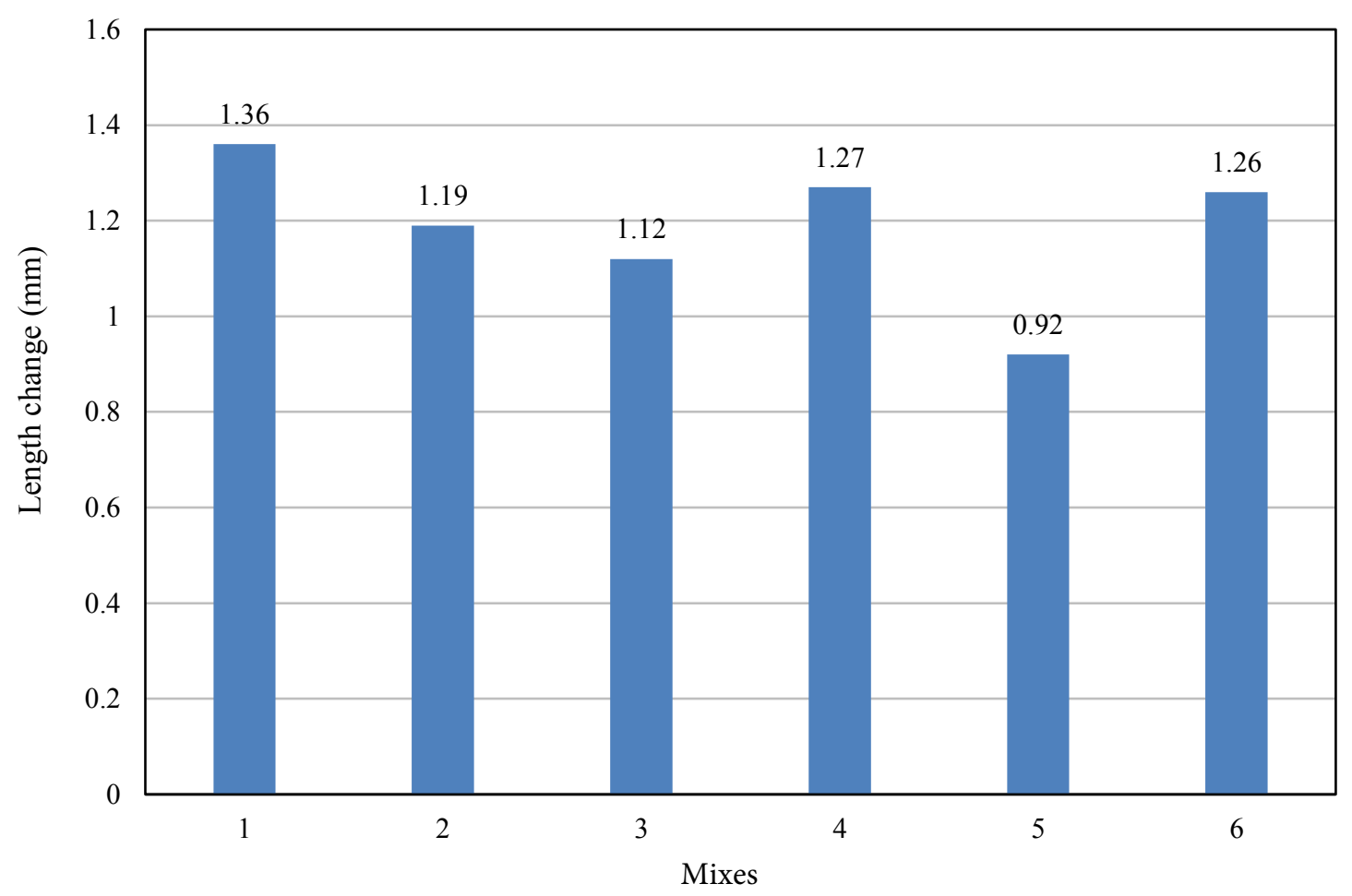

Fig. 3. Results of length change due to abrasion ( $\mathrm{mm})$.

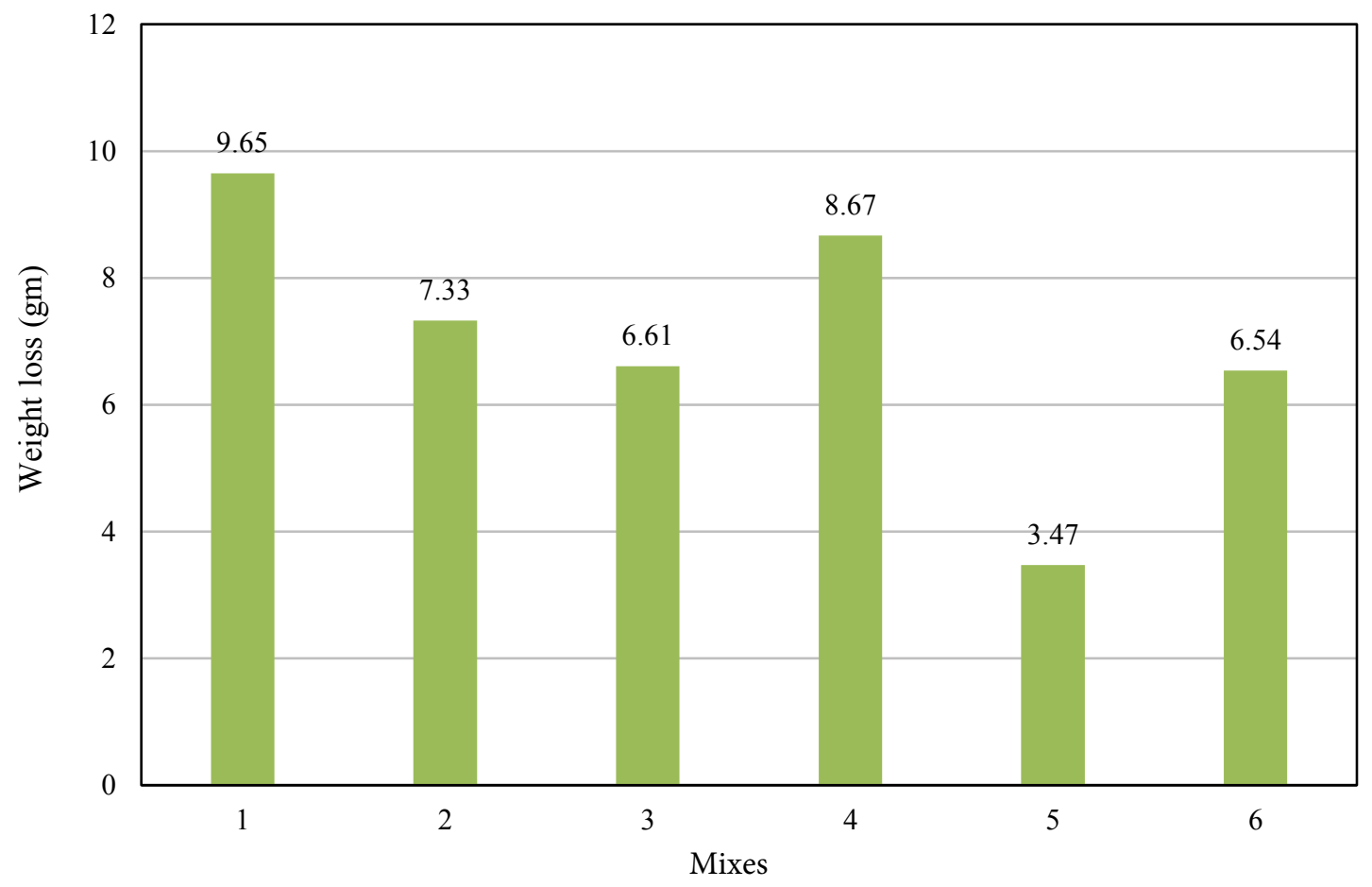

Fig. 4. Results of weight loss due to abrasion (gm). 


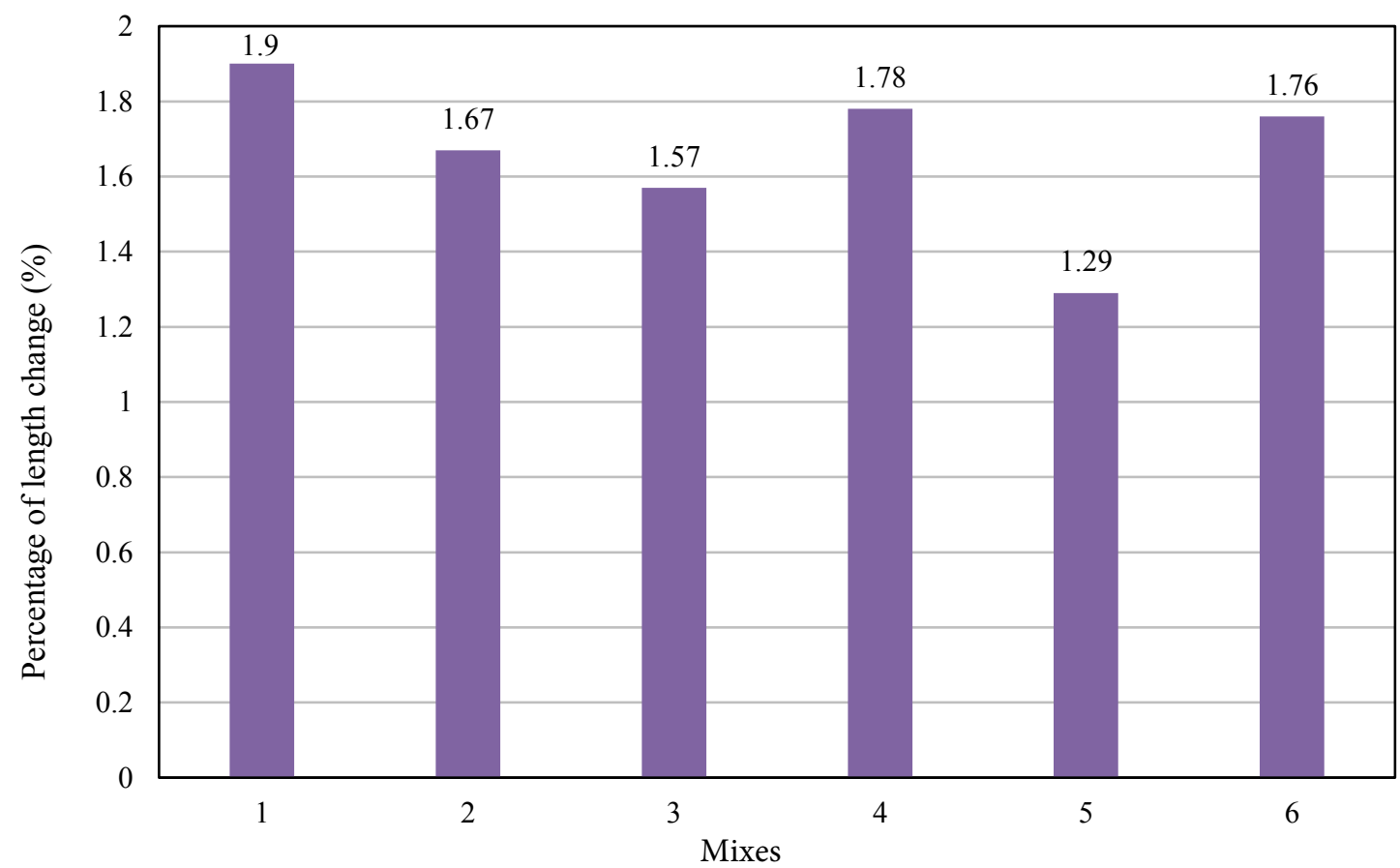

Fig. 5. Percentage of length change due to abrasion

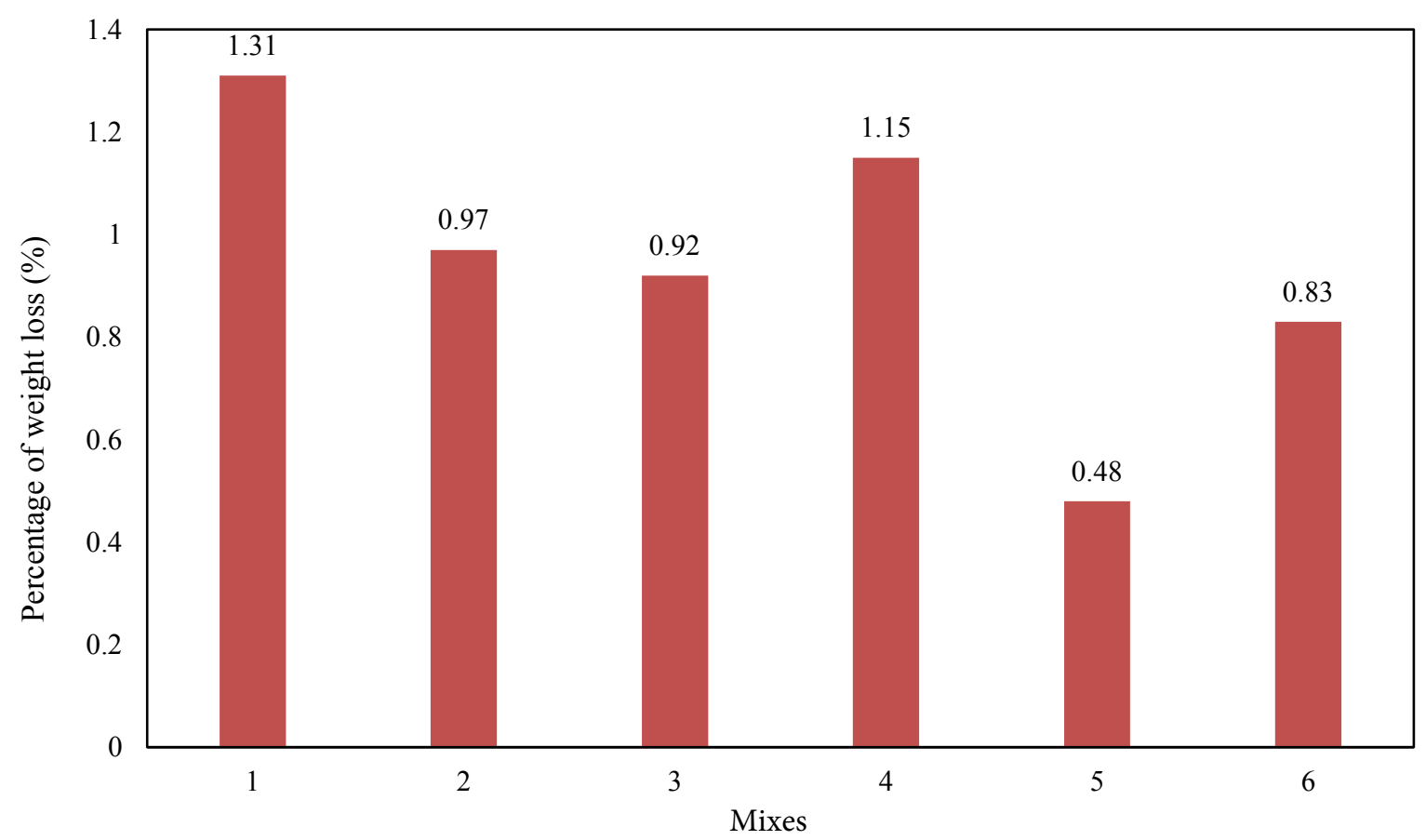

Fig. 6. Percentage of weight loss due to abrasion

\section{Conclusions}

In this paper, an experimental investigation was carried out to inspect the feasibility of using waste foundry sand and limestone as fine aggregates to manufacture non-fibrous and steel fiber reinforced mortars. Tests of strength properties and abrasion resistance were conducted on the manufactured mortars, the conclusions of this work could be drawn as follows:

- In general, the mixes with foundry sand and limestone yielded better results when compared to the control sample, they showed a significant improvement in all of the investigated tests.

- The mix with foundry sand and steel fibers yielded the best results in all of the tests, it showed a compressive strength improvement of $22.33 \%, 35.56 \%$ in flexural strength, $0.92 \mathrm{~mm}$ in terms of length change and $3.47 \mathrm{gr}$ in terms of weight loss. 
- The limestone mixes showed an acceptable performance in compressive strength and abrasion resistance and presented a significant improvement in flexural strength.

- Using waste materials such foundry sand proved to be in benefit of enhancing the properties of the manufactured mortars from the strength perspective as well as the economical and the environmental aspects.

\section{Acknowledgment}

This work was supported by research fund of the Yildiz Technical University, the authors would like to express their sincere gratitude to scientific research coordination unit for their financial support to the project (Project number: 2016-05-01-YL01).

\section{References}

1. Bhardwaj B, Kumar P. Waste foundry sand in concrete: A review. Constr Build Mater. 2017;156:661-674. doi:10.1016/j.conbuildmat.2017.09.010.

2. Dolage DAR, Dias MGS, Ariyawansa CT. Offshore Sand as a Fine Aggregate for Concrete Production. Br J Appl Sci Technol. 2013;3(4):813-825.

3. Carlos A, Masumi I, Hiroaki M, Maki M, Takahisa O. The effects of limestone aggregate on concrete properties. Constr Build Mater. 2010;24(12):2363-2368. doi:10.1016/j.conbuildmat.2010.05.008.

4. Baran M, Bilir T, Canbay E. Use of steel fiber reinforced mortar for seismic strengthening. Constr Build Mater J. 2011;25:892-899. doi:10.1016/j.conbuildmat.2010.06.096.

5. Bentur A. Fiber-reinforced cementitious materials. Material science concrete. Ohio: The American Ceramic Society; 1989.

6. Bentur A., Mindeness S. fiber reinforced cementitious composites New York: Elsevier Applied Science; 1990.

7. Pierre P, Pleau R, Pigeon M. Mechanical properties of steel microfiber reinforced cement pastes and mortars. J Mater Civil Eng 1999; 11(4):317-24.

8. BS EN 196-1(2016), BSI Standards Publication Methods of testing cement Part 1: Determination of strength.

9. ASTM. (2010). Standard Test Method for Compressive Strength of Hydraulic Cement Mortars (Using 2-in. or [50-mm] Cube Specimens) 1. Chemical Analysis, (C109/C109M - 11b), 1-9. https://doi.org/10.1520/C0109

10. ASTM C348. (1998). Standard Test Method for Flexural Strength of Hydraulic-Cement Mortars ASTM C348. Annual Book of ASTM Standards, 4, 2-7. https://doi.org/10.1520/C0348-14.2

11. European Standard, EN 1338. Concrete paving blocks - requirements and test, methods; 2003. 